\title{
Peculiarities of Surface Interaction of Al+REM Alloys with Air and Water
}

\author{
N.A. Popov", L.A. Akashev, V.G. Shevchenko, I.G. Grigorov \\ Institute of Solid State Chemistry, Ural Branch of RAS, Russia
}

Copyright $\bigcirc 2017$ by authors, all rights reserved. Authors agree that this article remains permanently open access under the terms of the Creative Commons Attribution License 4.0 International License

\begin{abstract}
The effect of the phase and chemical composition of aluminium+rare earth metal $(1-2.5 \% \mathrm{R}$, $\sim 22 \% \mathrm{R}$ ) polycrystalline alloys ( $\mathrm{Al}+\mathrm{REM}$ ) on the rate of their surface film growth in air (at temperatures $400,500,600^{\circ} \mathrm{C}$ ) and in water $\left(\sim 100^{\circ} \mathrm{C}\right)$ was studied. It is shown that in the temperature range $500-600^{\circ} \mathrm{C}$ the oxidation of $1-2.5 \% \mathrm{R}$ alloys in air is enhanced due to the increasing amount of REM oxide phases and crystallization of amorphous $\mathrm{Al}_{2} \mathrm{O}_{3}$. $\mathrm{Al}+1$ at. $\% \mathrm{Yb}$ alloy shows the lowest oxidation stability in this temperature range owing to the formation of the greatest amount of REM oxides. Oxidation of Al+REM $(\sim 22 \% \mathrm{R})$ alloys in air begins at a temperature below $400^{\circ} \mathrm{C}$. Their oxidation rate depends on the type and amount of dopant metal and the phase composition: the presence of REM-rich intermetallics in the alloy dramatically increases its reactivity. It is established that in the interaction of $\mathrm{Al}+\mathrm{REM}$ alloys with boiling water, the active reacting phase is aluminum.
\end{abstract}

Keywords Aluminium-rare Earths Alloys, Ellipsometry, Oxide Film Growth

\section{Introduction}

Aluminum alloys with rare earth metals (REM) find wide application in electrical engineering. Small amounts (up to at.5\%) of transition ( $\mathrm{Zr})$ or rare-earth metal (Sc, Y and lanthanides) dopants increase the strength of aluminum applied in high-strength power lines. Due to low solubility of these metals in aluminum, its electrical conductivity is preserved. The finely dispersed phase of intermetallic compounds $\mathrm{Al}_{11} \mathrm{R}_{3}\left(\mathrm{Al}_{3} \mathrm{R}\right)$ formed in the aluminum alloy increases its strength almost twice [1]. Additives reinforcing aluminum (for example, copper in duralumin) often impair its resistance to corrosion. One of the reasons of this is a variation in the chemical composition and structure of the passivating oxide films. Therefore, the study of the protective properties of oxide films of aluminum alloys is not less important than the study of their strength and electrical properties. The information about the properties of protective passivating oxide films at elevated temperatures can be used for the development of new high-temperature (up to $300^{\circ} \mathrm{C}$ ) uninsulated wires and wires operating at elevated humidity.

Besides, the prospects of using rare-earth metals as alloying additions increasing the oxidation rate of aluminum powder in rocket propellants were shown by authors of works $[2,3]$. Small additions of rare earth metals improve the burning rate and other impulse characteristics of disperse aluminum by reducing the protective properties of its oxide film. Because of this, it is important to study the effect of rare earth additives on the thermokinetic characteristics of aluminum, including cracking of the barrier layer of oxidation products on the metal surface.

\section{Experimental Section}

To determine the quantitative effect of the chemical and phase composition of alloys on the intensity of their interaction with reactive media (air, water), two groups of alloys were synthesized: alloys close to eutectics $(\mathrm{Al}+1-2,5 \% \mathrm{R})$ and alloys with chemical composition close to aluminum in intermetallides $\mathrm{Al}_{11} \mathrm{R}_{3}(\sim 22 \% \mathrm{R})$. All samples were synthesized by melting in a vacuum furnace in helium environment (high purity grade) at $1500^{\circ} \mathrm{C}$ followed by cooling in alundum crucibles. The composition of the alloys was refined by mass spectrometry (Spectromass 2000) and X-ray fluorescence spectroscopy (XRF-1800). The investigated sample surface was the top plane polished mechanically. The alloys were polished by diamond pastes applied on soft fabrics until a specular reflection was obtained (surface roughness was $\mathrm{Ra}=0.047-0.051 \mu \mathrm{m}$. Then the samples were washed thoroughly with alcohol and acetone with additional annealing in vacuum $(\sim 0,01 \mathrm{~Pa})$ at $300^{\circ} \mathrm{C}$ for $1 \mathrm{~h}$. The alloys were oxidized in air in a muffle furnace at temperatures of 400,500 and $600^{\circ} \mathrm{C}$. In all the experiments, the oxidation of alloys took place stepwise at the same temperature at 5, 10, 15 etc. min. intervals with 
windows for measurements. The interaction of water with the surface of $\mathrm{Al}+\mathrm{REM}$ alloys was realized by immersing the samples in boiling distilled water at $100^{\circ} \mathrm{C}$ with the same intervals for ellipsometric measurements in air.

The ellipsometric parameters $\Delta$ and $\psi$ were measured by the compensating (zero) method with a one-wave ellipsometer LEF-3M $(\lambda=0.6328 \mu \mathrm{m})$ after the samples were cooled in air to room temperature. Thereby the time dependence of the ellipsometric parameters of the examined surface in quasi-isothermal conditions was obtained.

To determine the kinetics of surface film growth (thickness against time), at first the optical constants $(n, k)$ of the alloys and their natural passivation films were found. For this purpose, we used the ellipsometric immersion method [4, 5]. The immersion liquids were anise oil $(\mathrm{n}=1.5)$ and alcohol $(n=1.364)$.

\section{Results and Discussion}

\subsection{Thermal Oxidation of the Alloys in Air}

Table 1 lists the refractive indices $\left(\mathrm{n}_{2}\right)$ and extinction coefficients $\left(\mathrm{k}_{2}\right)$ of pure aluminum, alloys of intermetallic and eutectic compositions, as well as of their natural oxide films $\left(\mathrm{n}_{1}, \mathrm{k}_{1}\right)$ with the initial thickness $\mathrm{d}$. It is seen that the thickness of the oxide layer on the alloys is always higher than on pure aluminum. Besides, the optical constants of substrates for the two groups of alloys differ considerably from each other due to different phase composition.

Table 1. Chemical composition and optical constants of Al+REM alloys

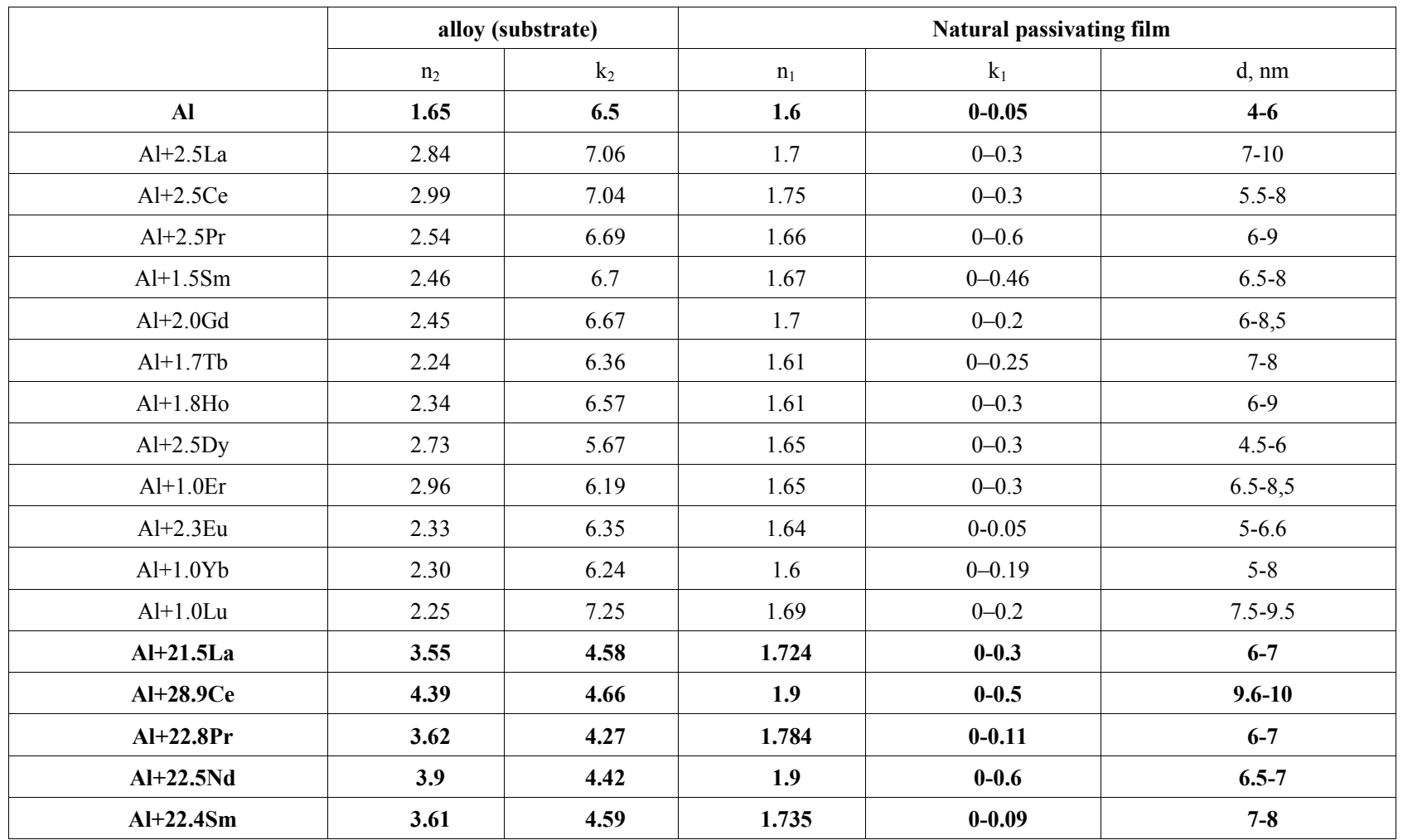




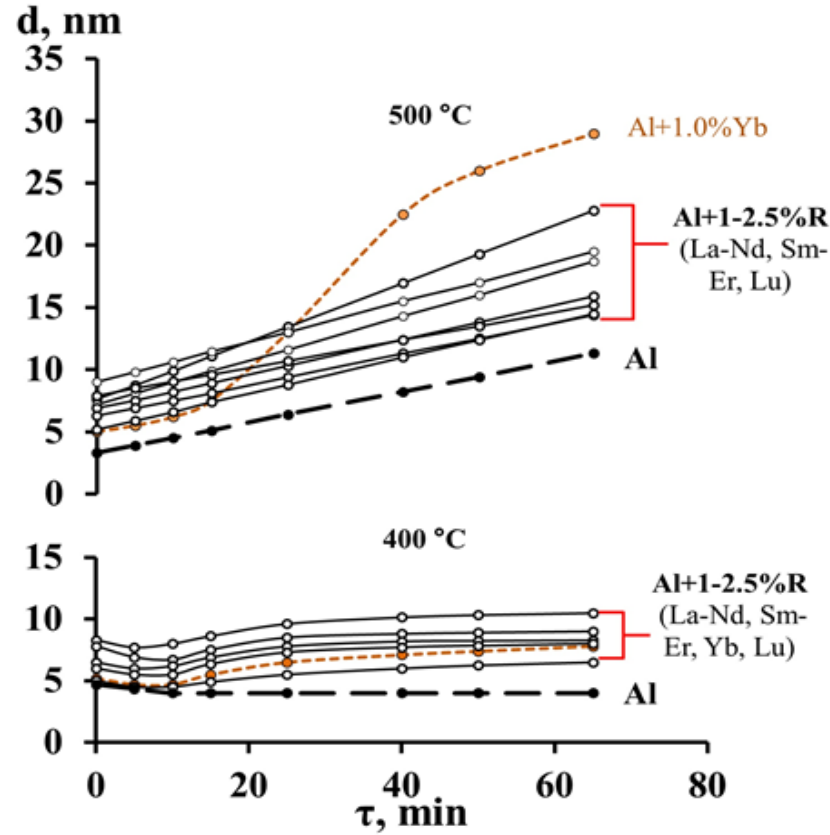

a)

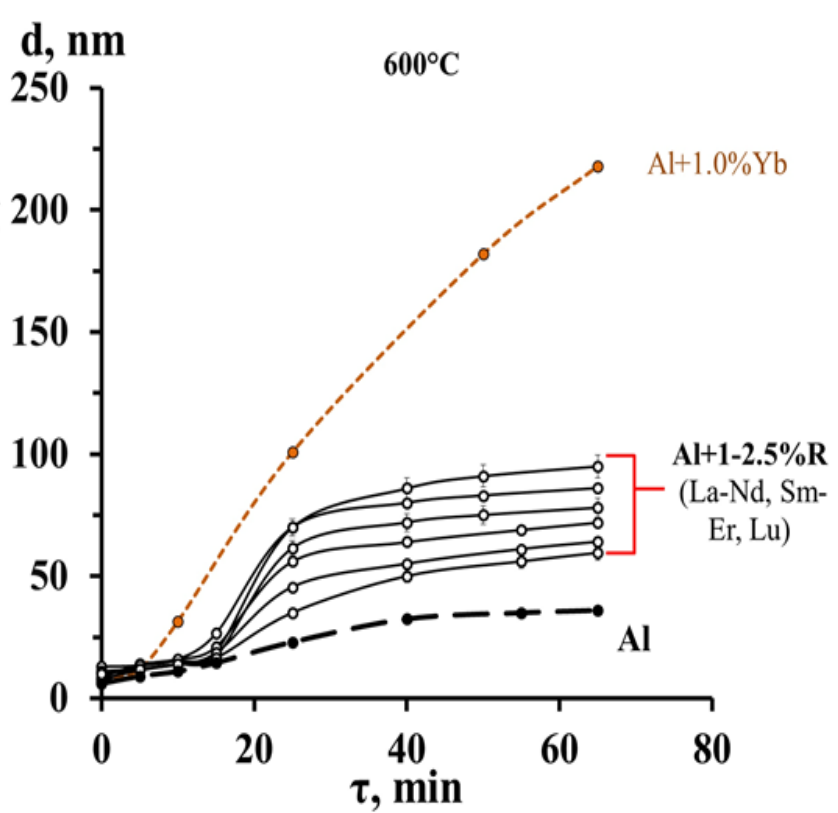

b)

Figure 1. Temperature and time dependences of the oxide film thickness growth on $\mathrm{Al}+1-2.5 \% \mathrm{R}$ alloys at 400,500 (a), and $600^{\circ} \mathrm{C}$ (b) in air

Figure 1(a,b) presents the temperature and time dependences of the thickness growth of oxide films as oxidation products. The thickness of the oxide film on the $\mathrm{Al}+1-2.5 \% \mathrm{R}$ alloys is higher than on pure $\mathrm{Al}$ and increases with temperature. There are several stages at each temperature. The oxidation of the $\mathrm{Al}+1-2.5 \% \mathrm{R}$ alloys at $400^{\circ} \mathrm{C}$ (Fig.1a) for $15 \mathrm{~min}$ is characterized by thermal desorption of water molecules and carbonates adsorbed from air. During long-term annealing, the increase in the oxide thickness is less than $4 \mathrm{~nm}$ per hour. When the temperature is raised to $500^{\circ} \mathrm{C}$, a more active growth of the oxide film is observed. Thermal desorption takes less than $5 \mathrm{~min}$, therefore it is not marked on the curves. After $1 \mathrm{~h}$ exposure at $500^{\circ} \mathrm{C}$ and $600^{\circ} \mathrm{C}$ (fig. $1 \mathrm{~b}$ ), the greatest increase in the film thickness was observed for the alloy with ytterbium $(1 \% \mathrm{Yb})$. At $600^{\circ} \mathrm{C}$, during the first 25 minutes of exposure, a sharp increase in the oxide film thickness takes place for the majority of $\mathrm{Al}+1-2.5 \mathrm{at} . \% \mathrm{R}$ alloys (Fig. 1b).

Detailed analysis of the curves shows that the sharp thickness growth is due to crystallization of the natural (amorphous) aluminum oxide film in $\gamma-\mathrm{Al}_{2} \mathrm{O}_{3}$. Aluminum oxide is a predominant component of the examined oxide films; it crystallizes forming grain boundaries that give way to oxygen particles to the alloy surface. According to different literature data [6-12], the temperature of the phase transformation of aluminum oxide falls within the range of $475-550{ }^{\circ} \mathrm{C}$.

Figures 2, 3 show the literature data proving that in the temperature interval $475-550^{\circ} \mathrm{C}$, on the surface of bulk [6] and finely-dispersed aluminum [12], the amorphous surface oxide film transforms into a crystalline gamma modification.

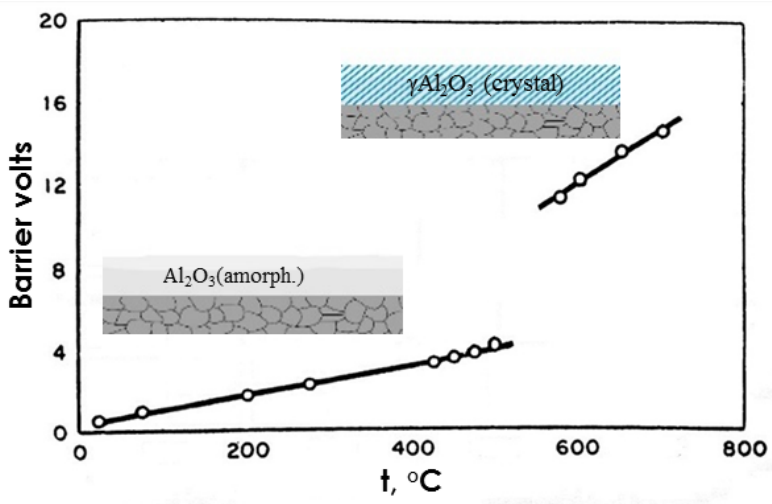

Figure 2. The growth of oxide film on bulk $\mathrm{Al}$ as a function of temperature [6]

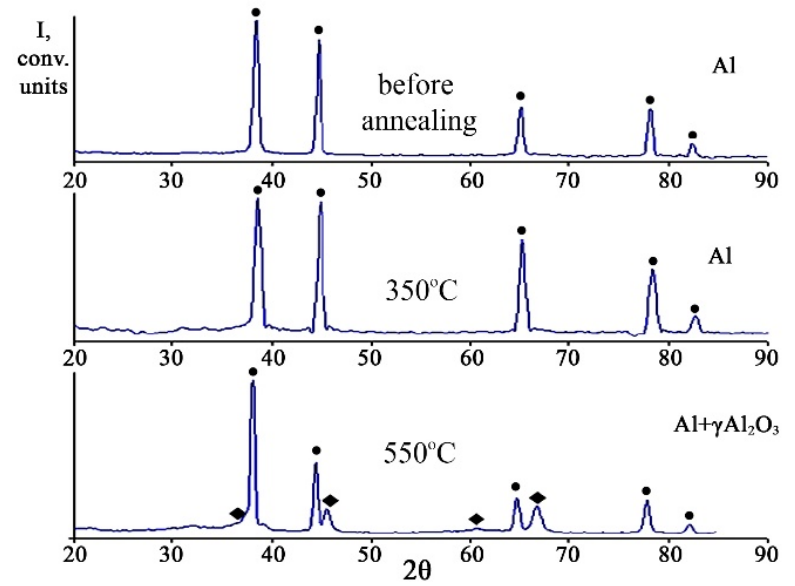

Figure 3. XRD diagram of aluminum nanopowder samples annealed in air for $1.5 \mathrm{~h}$ at $350^{\circ} \mathrm{C}$ and $550^{\circ} \mathrm{C}$ [12] 
The active thickness growth of the oxide film on $\mathrm{Al}+1 \% \mathrm{Yb}$ alloy (Figure 1a,b) can be explained as follows: in addition to crystallization of amorphous $\mathrm{Al}_{2} \mathrm{O}_{3}$, individual oxide phases $\mathrm{R}_{\mathrm{x}} \mathrm{O}_{\mathrm{y}}$ are formed in the films at these temperatures. The formation of $\mathrm{R}_{\mathrm{x}} \mathrm{O}_{\mathrm{y}}$ phases affects the continuity and overall thickness of the oxide film in the same way. This is particularly evident in the case of $\mathrm{Yb}$ oxides during oxidation of $\mathrm{Al}+1 \% \mathrm{Yb}$ alloy. In ref 10 , the study of ytterbium powder oxidation in air revealed that three oxide phases are present at once in the powder in a wide temperature range (from 250 to $650^{\circ} \mathrm{C}$ and higher): lower oxide $\mathrm{YbO}$ crystallizing in fcc structure (unlike lower oxides of other rare-earth metals formed in the bcc lattice), orthorhombic $\mathrm{Yb}_{3} \mathrm{O}_{4}$ found in the interval $300-650^{\circ} \mathrm{C}$, and sesquioxide bcc oxide $\mathrm{Yb}_{2} \mathrm{O}_{3}\left(>400^{\circ} \mathrm{C}\right)$.

Thus, in the temperatures interval $550-600^{\circ} \mathrm{C}$ the multiphase oxide film may contain at once three stoichiometric oxide phases (Figure 4), which was also confirmed by the maxima on the thermogravimetric curves [3].

Analysis of the available literature data [13-15] and our experimental findings shows that in the investigated temperature range, the oxidation of other rare earth metals (lanthanides) is accompanied by the formation of maximum two stoichiometric oxide phases (Figure 4). So, oxides of elements from $\mathrm{Nd}$ to $\mathrm{Lu}$ are usually formed as higher $\mathrm{R}_{2} \mathrm{O}_{3}$ oxide (typical valence of REM is $3+$ ) having a bcc lattice. In the case of $\mathrm{La}, \mathrm{Ce}, \mathrm{Pr}$, the following structural phase transitions are possible: $\mathrm{La}$ (bcc $\mathrm{La}_{2} \mathrm{O}_{3} \stackrel{>550^{\circ} \mathrm{C}}{\longrightarrow}$ hcp $\mathrm{La}_{2} \mathrm{O}_{3}$ ),

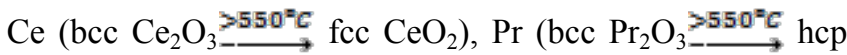
$\operatorname{Pr}_{2} \mathrm{O}_{3}$ ). Thus, it is shown that the main reason of increasing the oxidation rate of $\mathrm{Al}+1-2.5 \% \mathrm{R}$ alloys at $\mathrm{t}>500^{\circ} \mathrm{C}$ is the growth of interfaces of individual oxides

Oxidation of the alloys with a high content of REM ( $\sim 22$ at.\%R) begins at lower temperatures $\left(400^{\circ} \mathrm{C}\right)($ Fig. 5). The time dependences of the films thicknesses contain the curves for the alloys with large and small additions of REM at $400^{\circ} \mathrm{C}$ and $500^{\circ} \mathrm{C}$. It is seen that the increase in temperature by 100 degrees leads to 2-3 times enhancement of the oxide film thickness. At $600^{\circ} \mathrm{C}$, after $5 \mathrm{~min}$ exposure in the furnace, a strong interference of the reflected beam is observed for the surface of intermetallic compounds, which is associated with a dramatic thickening of the oxide film.

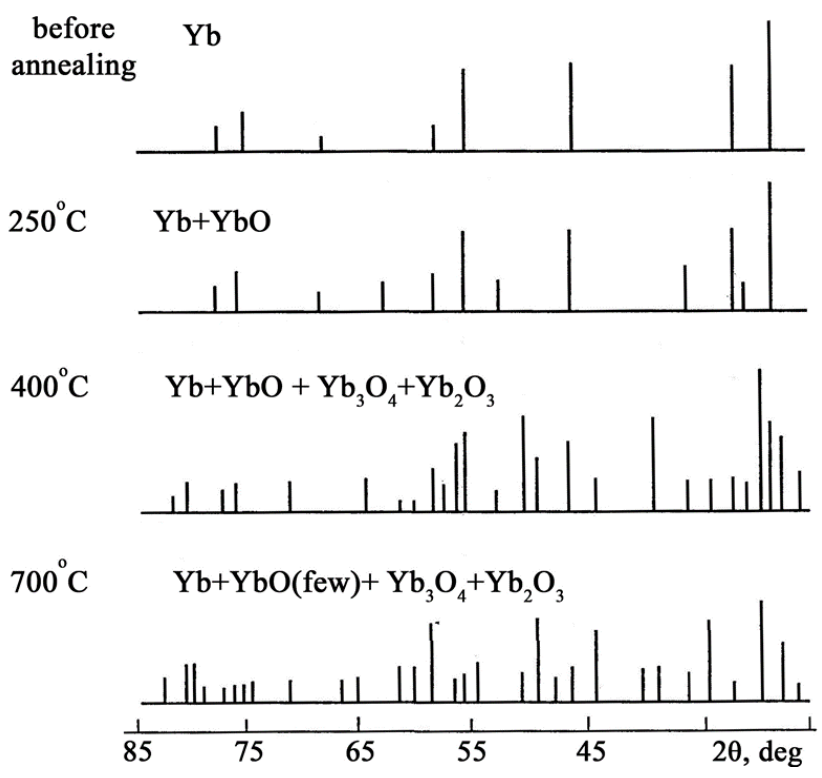

Figure 4. XRD diagrams of ytterbium powder at different temperatures [3]

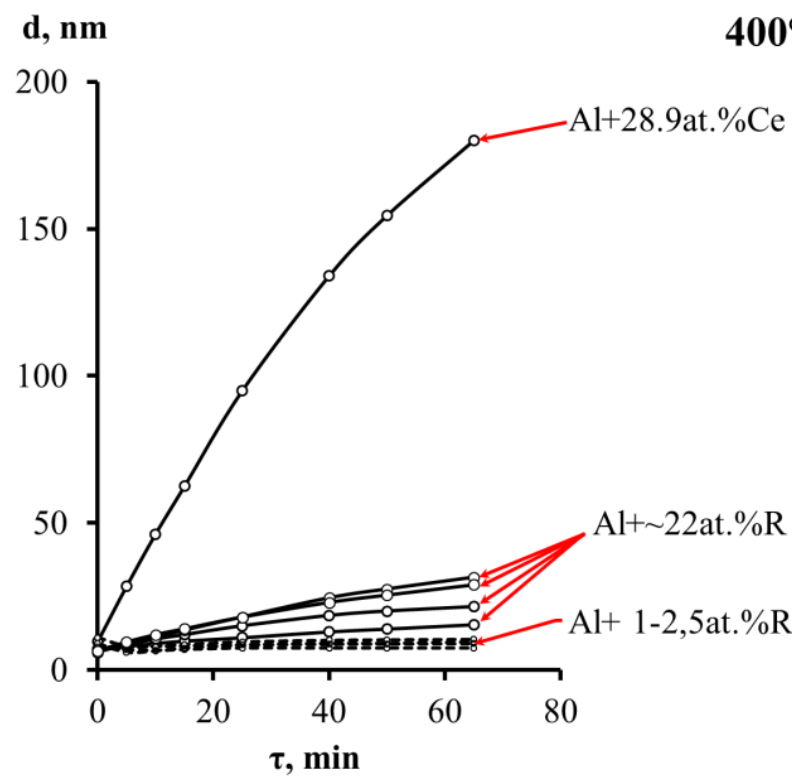

a) $400^{\circ} \mathrm{C} \mathrm{d}, \mathrm{nm}$

$500^{\circ} \mathrm{C}$

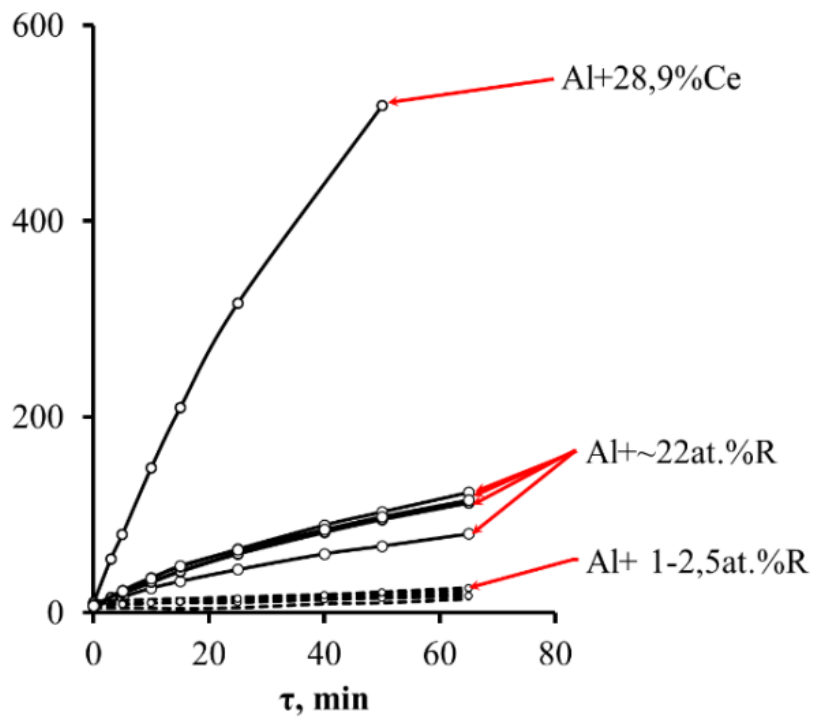

b)

Figure 5. Time dependence of the thickness of oxide films on aluminum alloys $\mathrm{Al}+\sim 22 \mathrm{at} . \% \mathrm{R}$ at 400 (a) and $500^{\circ} \mathrm{C}$ (b) in air. 

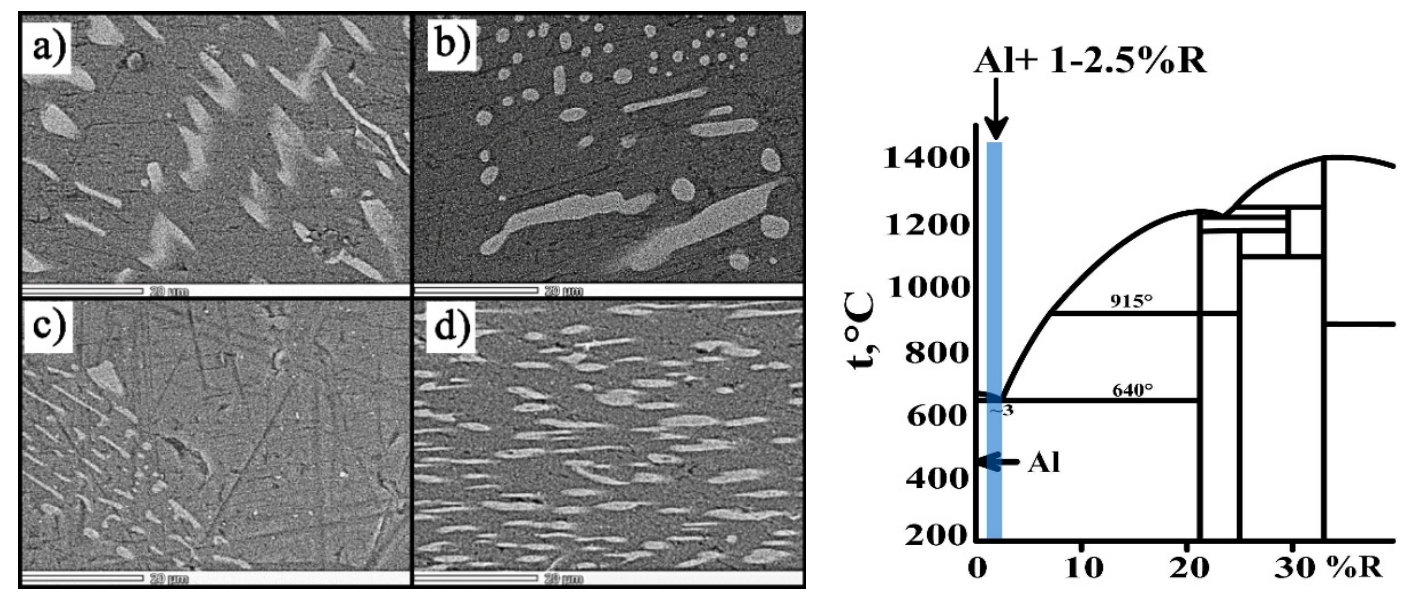

Figure 6. The micrographs of the surfaces of $\mathrm{Al}+1-2.5$ at.\%R alloys: a) $\mathrm{Al}+2.57$ at.\%La; b) $\mathrm{Al}+2.57$ at.\%Ce; c) $\mathrm{Al}+2.54 \mathrm{at} . \% \mathrm{Pr} ; \mathrm{d}) \mathrm{Al}+1.5 \mathrm{at} . \% \mathrm{Sm}$
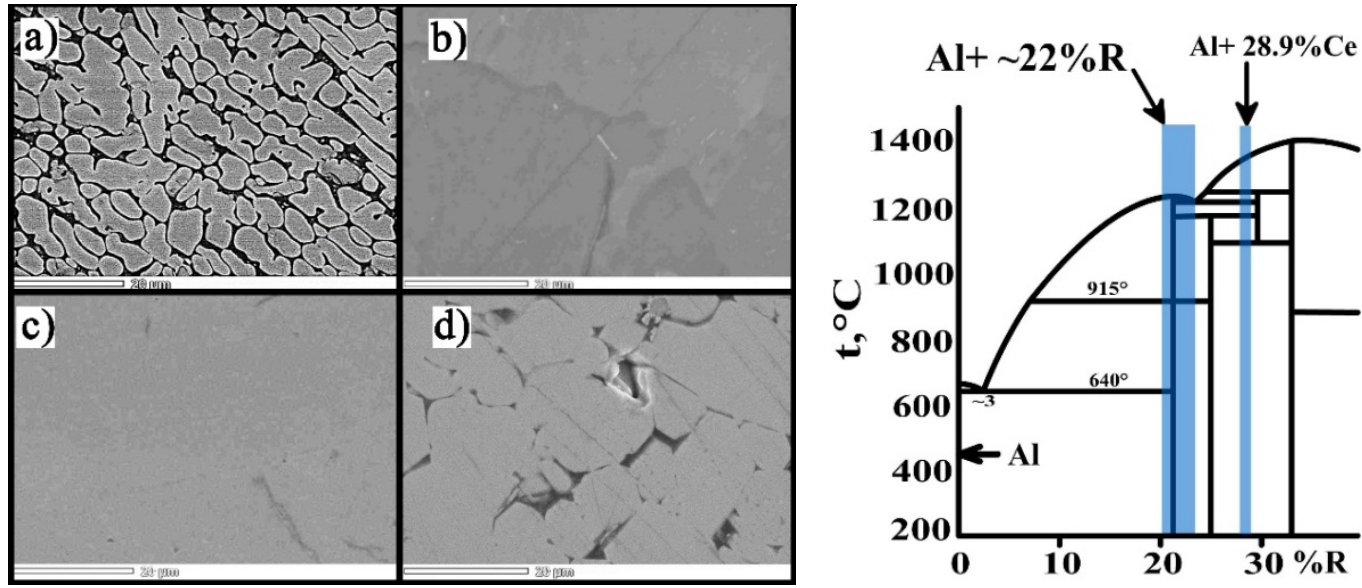

Figure 7. The micrographs of the surfaces of $\mathrm{Al}+22$ at. $\% \mathrm{R}$ alloys: a) $\mathrm{Al}+21.5$ at. $\% \mathrm{La}, \mathbf{b}) \mathrm{Al}+28.9$ at. $\% \mathrm{Ce}, \mathbf{c}) \mathrm{Al}+22.8$ at. $\% \mathrm{Pr}, \mathbf{d}) \mathrm{Al}+22.4 \mathrm{at} . \% \mathrm{Sm}$

Analysis of the equilibrium diagrams [13] and micrographs of the alloy surface showed that the film growth rate depends on the phase composition of the alloy. The main phase in the structure of $\mathrm{Al}+1-2.5 \% \mathrm{R}$ alloys (Figure 6) is aluminum (rare earth metals have a very low solubility in aluminum). The rare earth metal is present in the structure of these alloys in the form of intermetallic inclusions.

The structures of the alloys with a high content of REM differ from each other. So, in the structure of $\mathrm{Al}+21.5 \% \mathrm{La}$ and $\mathrm{Al}+22.4 \% \mathrm{Sm}$ alloys (Figure $7 \mathrm{a}, \mathrm{d}$ ), grains of intermetallic compounds dominate (hypereutectic region of the diagram) - these phases have the greatest affinity for atmospheric oxygen. Therefore, the film thickness on their surface is considerably higher (Figure 5).

On the phase diagram, the alloys $\mathrm{Al}+22.8 \% \operatorname{Pr}$ (Figure $7 \mathrm{~b}$ ) and $\mathrm{Al}+22.5 \% \mathrm{Nd}$ are exclusively in the region of intermetallic compounds, as seen from their structure. The thickness of their oxide films will be slightly higher than in the hypereutectic region. When the rare earth metal content increases further as in the $\mathrm{Al}+28.9 \% \mathrm{Ce}$ alloy, the alloy enters into the two-phase region $\mathrm{Al}_{3} \mathrm{R}-\mathrm{Al}_{2} \mathrm{R}$. Due to the presence of $\mathrm{Al}_{2} \mathrm{Ce}$ phase, the $\mathrm{Al}+28.9 \% \mathrm{Ce}$ alloy exhibits a high activity during thermal oxidation in air (Figure 5). Thus, it is seen that the presence of REM-rich phases dramatically increases the oxidation rate of $\mathrm{Al}+\mathrm{R}$ alloys.

\subsection{Interaction with Boiling Water}

The opposite character of interaction was observed in the study of the interaction of Al+REM surface with boiling water. According to the IR spectroscopy and X-ray analysis results, the main product of the reaction on the $\mathrm{Al}$ and $\mathrm{Al}+\mathrm{REM}$ alloys surface in these conditions is the $\mathrm{AlOOH}$ hydroxide film. The thicknesses were calculated from the ellipsometric parameters $\Delta$ and $\psi$ on the basis of the two-layer model: substrate - oxide film - hydroxide film $(\mathrm{n}=1.56)$. Figure 8 shows the time dependence of the surface film thickness growth. It is seen that the rate of the formation of reaction products on the surface of pure aluminum and $\mathrm{Al}+1-2.5 \% \mathrm{R}$ alloys is higher than on the surface of intermetallic compounds. Small additions of REM in aluminum affect little the thickness of films produced in these conditions on its surface. The ellipsometric parameters at the initial stages of interaction (1-3 $\mathrm{min}$ ) are described well by a two-layer model with an inhomogeneous (porous) film of the upper layer of aluminum hydroxide. At further boiling, the layer is compacted, as a result of which it grows already at a slower rate. After $65 \mathrm{~min}$ interaction with distilled water, 
the film thickness on aluminum reaches $270 \mathrm{~nm}$, while on the $\mathrm{Al}+1-2.5 \% \mathrm{R}$ alloys it is slightly smaller. As can be seen, after 65 min boiling the formation of films on the alloys is not completed.

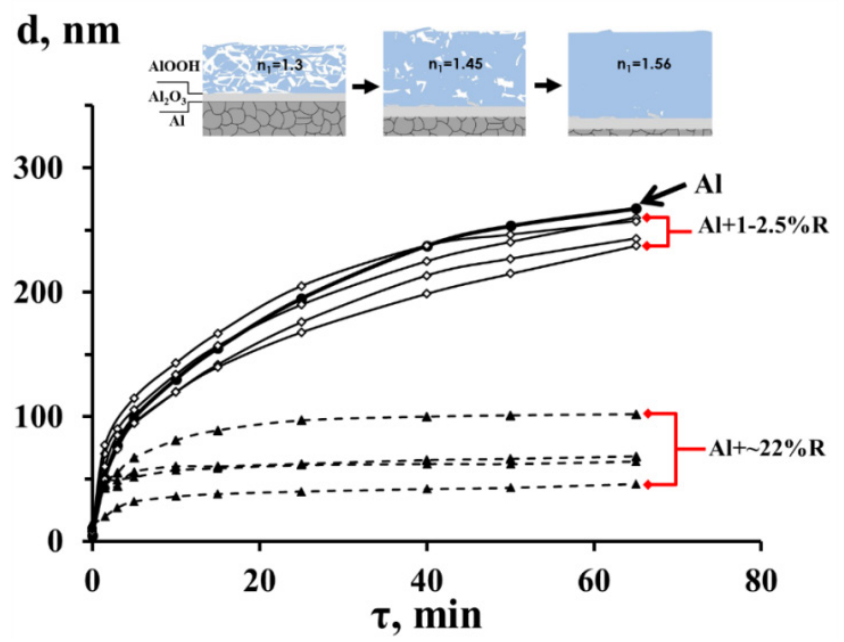

Figure 8. The time dependence of thicknesses of oxide-hydroxide films on $\mathrm{Al}$ and $\mathrm{Al}+\mathrm{REM}$ alloys during interaction with distilled water at $100^{\circ} \mathrm{C}$.

For $\mathrm{Al}+22 \% \mathrm{R}$ alloys, the interaction takes place at a much lower rate due to a significantly smaller content of aluminum metal (solid solution) in the bulk and on the surface of these alloys. The films on their surface turned out to be 2.5 times thinner during this period of time, thus there was no noticeable film growth (Figure 8 ).

The presence of a porous film formed on the surface of eutectic alloys and pure aluminum after 1-3 min boiling in distilled water was confirmed by atomic force microscopy.

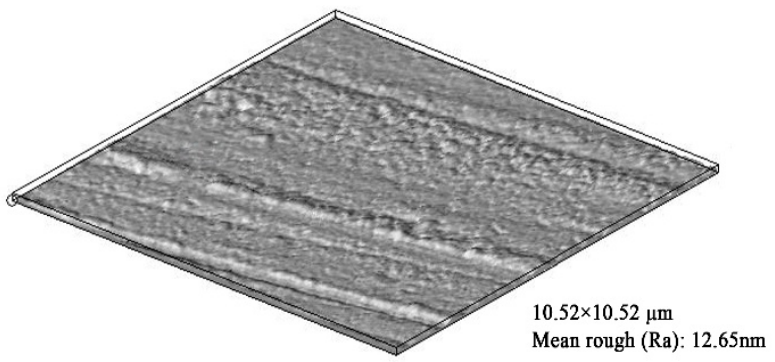

a)
As seen in Figure 9, a raised roughness is detected on the aluminum surface after $1.5 \mathrm{~min}$ interaction (average roughness $\mathrm{Ra}=\sim 12.7 \mathrm{~nm}$ ), which may be indicative of a porous structure of aluminum hydroxide on the surface at the initial stage of interaction. The stripes are the traces of pre-mechanical polishing of the surface. The sample of aluminum intermetallic with praseodymium (Fig. 9b) has a much smaller average roughness $\mathrm{Ra}=\sim 6.3 \mathrm{~nm}$ under these conditions.

Note that before and after $1.5 \mathrm{~min}$ interaction the $\mathrm{Al}+\sim$ 22at.\%R alloys visually retain their mirror surface. The surface of aluminum and $\mathrm{Al}+1-2.5 \% \mathrm{R}$ quickly gets cloudy.

The alloy powders prepared by mechanical grinding of monolithic ingots in a mortar and by screening on laboratory sieves (diameter of grains $<63 \mu \mathrm{m}$ ) were boiled for $65 \mathrm{~min}$ under the same conditions. Figure 10 shows the IR spectra of the powders obtained for all the investigated alloys. The intensity of the absorption bands is weak because of low dispersion. However, on the spectra of $\mathrm{Al}+1-2.5 \mathrm{at} \% \mathrm{R}$ powders one can identify the absorption bands corresponding to stretching, deformation and libration vibrations of $\mathrm{OH}-$ bonds in aluminum hydroxide $\left(3433 \mathrm{~cm}^{-1}\right.$, $1631 \mathrm{~cm}^{-1}, 1078 \mathrm{~cm}^{-1}$, respectively). In all the IR spectra of $\mathrm{Al}+\sim 22 \% \mathrm{R}$ alloys, the absorbtion band at $1078 \mathrm{~cm}^{-1}$ is faint or absent, which is indicative of a small amount of hydroxide forming the surface film. Proceeding from the surface morphology of the samples, it can be supposed that metallic aluminum in these alloys in water at $100^{\circ} \mathrm{C}$ is the main reactive phase, and when its content in the bulk and on the alloy surface decreases, the amount of hydroxide forming the surface film lowers.

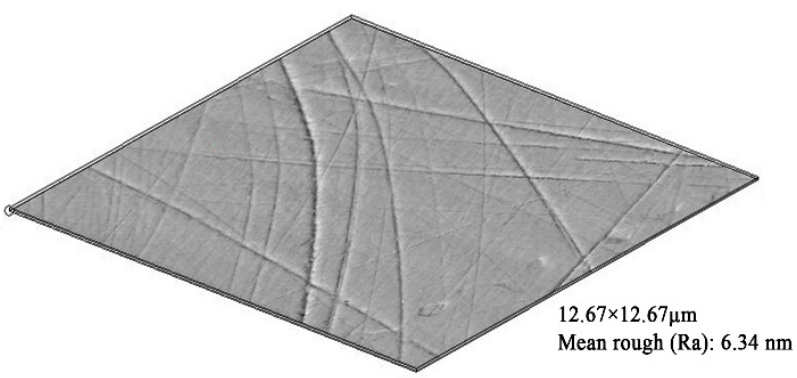

b)

Figure 9. a) AFM picture of aluminum surface after 1.5 min interaction with water. b) AFM photograph of the surface of the intermetallic compound Al+ 22.8 at. \% Pr after 1.5 min interaction with water (the stripes are polishing defects). 


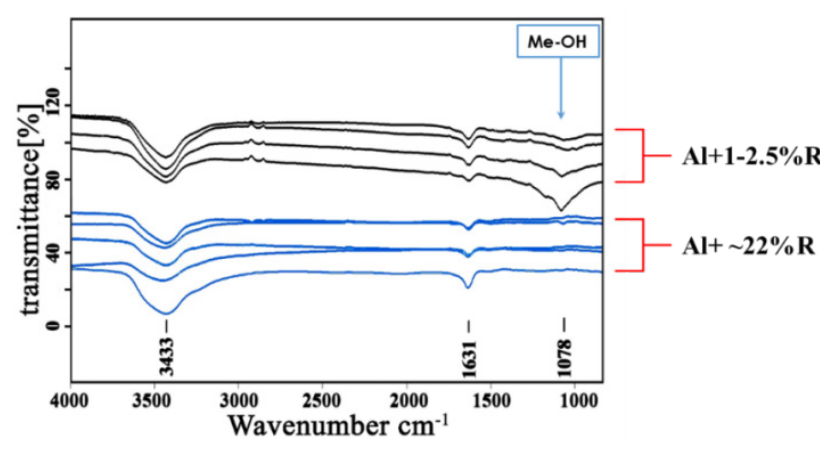

Figure 10. The infrared transmission spectra of powders of Al+REM alloys after 65 min contact with boiling water

\section{Conclusions}

The peculiarities of the surface interaction of Al+REM alloys with oxygen at 400,500 , and $600^{\circ} \mathrm{C}$ and with boiling water were studied. For $\mathrm{Al}+1-2.5 \% \mathrm{R}$ alloys, in the temperature range from 500 to $600^{\circ} \mathrm{C}$ oxidation in air is enhanced due to the increasing amount of $\mathrm{R}_{\mathrm{x}} \mathrm{O}_{\mathrm{y}}$ oxide phases and crystallization of amorphous $\mathrm{Al}_{2} \mathrm{O}_{3}$ inside the surface film. The $\mathrm{Al}+1 \% \mathrm{Yb}$ alloy has the lowest oxidation stability in this temperature range owing to the formation of the greatest amount of REM oxides.

The oxidation of $\mathrm{Al}+\sim 22 \% \mathrm{R}$ alloy in air begins at a temperature below $400^{\circ} \mathrm{C}$. The oxidation rate depends on the type and amount of the alloying metal and the phase composition: the presence of REM-rich phase dramatically increases the oxidation rate of $\mathrm{Al}+\mathrm{R}$ alloys.

It is found that in the interaction of Al+REM alloys with boiling water, the active reacting phase is pure aluminum.

\section{REFERENCES}

[1] Matveeva, I., Dovzhenko, N., Sidelnikov, S. [et al.]. Development and Research of New Aluminium Alloys with Transition and Rare-Earth Metals and Equipment for Production of Wire for Electrotechnical Applications by Methods of Combined Processing. Proceed. of the symposia "Light metals 2013». -New Jersey: John Wiley \& Sons Inc., 2013, 443-447.
[2] V.G. Shevchenko, Effect of alloying on the kinetics and mechanism of oxidation of powdered aluminum-based alloys with rare- and alkaline-earth metals, Combustion, Explosion, and Shock Waves. -2011. -V. (47) № 2. -P. 166-173.

[3] Kononenko, V.I., Shevchenko, V.G. Physicochemistry of activation of dispersed systems based on aluminum UrO RAN: Ekaterinburg, 2006. (in Russian)

[4] Egorova, G.A., Potapov, E.V., Rakov A.V. Ellipsometry of thin transparent films on aluminum. Optika i spektroskopiya. 1976, 41(4), 643-647 (in Russian).

[5] Egorova, G.A., Ivanova, N.S., Potapov, E.V., Rakov, A.V. Ellipsometry of subthin transparent films. Optika $i$ spektroskopiya. 1974, 36 (4), 773-776 (in Russian).

[6] Vargel, C. Corrosion of aluminium; Elsevier: Netherlands, 2004

[7] Hunter, M.S., Fowle, P. Natural and thermally oxide films on aluminum. J. Electrochem. Soc. 1956, 103. 482-485.

[8] Hunter, M.S., Fowle, P. Determination of barrier layer thickness of anodic oxide coatings. J. Electrochem. Soc. 1954, 101. 481-485.

[9] Trunov, M. A., Schoenitz, M., Zhu, X., Dreizin, E.L. Effect of polymorphic phase transformations in $\mathrm{Al}_{2} \mathrm{O}_{3}$ film on oxidation kinetics of aluminum powders. Combust and Flame. 2005, 140 (4), 310-318.

[10] Korshunov, A. V., Ilyin, A. P., Radishevskaya, N. I., Morozova, T. P. The kinetics of oxidation of aluminum electroexplosive nanopowders during heating in air. Rus. $J$ of Phys. Chem A, 2010, 84 (9), 1576-1584.

[11] Jeurgens, L. P. H., Sloof, W. G., Tichelaar, F. D., Mittemeijer, E. J. Growth kinetics and mechanisms of aluminum-oxide films formed by thermal oxidation of aluminum, J. Appl. Phys., 2002, 92, 1649.

[12] Korshunov, A.V., Ilyin, A.P. Effect of the state of oxide-hydroxide shell on the reactivity of aluminum nanoparticles, Proceed. of the Tomsk polytech. univ., 2008. 312(3), 11-15 (in Russian).

[13] Okamoto, H. Desk Handbook: Phase Diagrams for Binary Alloys; ASM International: Ohio, 1996.

[14] Glushkova, V.B. Polymorphism of oxides of rare-earth elements; Nauka: Leningrad, 1967 (in Russian).

[15] Gschneidner, K.A.; Eyring L. Handbook on the Physics and Chemistry of Rare Earths, Vol.3,4; North-Holland Publishing Company, 1979. 